\title{
An Application of the Cobb-Douglass Production Function in the Quantitative Assessment of the Productivity of a Manufacturing Firm in Nigeria
}

\author{
R.O. Edokpia ${ }^{1, *}$ and M. H. Oladeinde ${ }^{1}$ \\ ${ }^{1}$ Department of Production Engineering, University of Benin, Benin City, Nigeria \\ Corresponding Author: *ralphedokpia@yahoo.com
}

\begin{abstract}
The focus of this study is the use of the Cobb-Douglas' production function to evaluate the productivity of a manufacturing firm. In order to achieve our aim, secondary data of the production line of the firm, were used. These data include the production output data and cost data, which covered a period from 1991 to 2010. A production frontier was established for every manufacturing year using the production function. Business cycle was also used to analyze the deviation between the actual production and the production frontier. The results indicated that for 80 percent of the years under study, the firm operated above the production frontier, and therefore considered technically efficient for those years, with the exception of the years 1994, 2005, 2007 and 2008 where the firm operated below the production frontier. Also the deviation between the actual production and the production frontier followed the business cycle. The trend of actual production curve showed that there is a tendency of low productivity in the future.
\end{abstract}

Keywords: Output Elasticity, Labour, Capital, Cobb-Douglas Model, Production Function, Recession and Depression

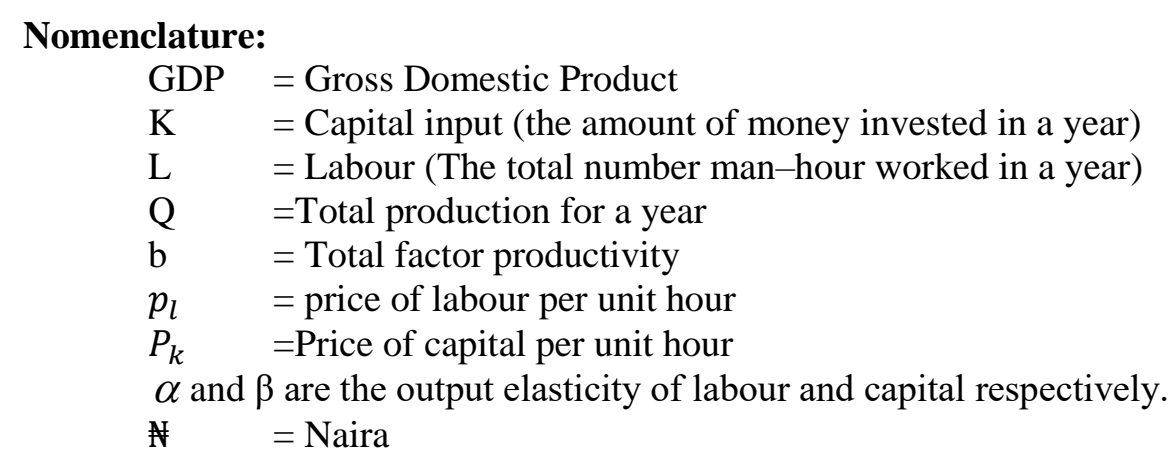

\subsection{Introduction}

In fact, the manufacturing sector, according to the report on Vision 2020 NTWG on Manufacturing Thematic Area (2009), has performed woefully and failed to deliver on its high potentials as reflected by low capacity utilization, minimal economic contribution to the country's GDP (from $8.8 \%$ in 1990 to $4.1 \%$ as at 2008) and low employment share in comparison to other sectors. Over the years, estimated cost of production in the Nigeria has risen considerably due to the high cost of doing business. The Nigerian economy depends on oil revenue and the country has large oil reserves and therefore has great potential to build a strong and vibrant economy from huge revenues generated from this sector. In fact, it has been reported that as at $2009,95 \%$ of the country's foreign exchange earnings derives from oil. However, these revenues failed to improve the poverty level of the country and it was among the world's poorest countries until 2002 ( $\mathrm{Ku}$ et al, 2010). In order to accelerate the growth of its economy, the country should reduce her dependence on oil and concentrate on the development of other sectors like agriculture, energy and, transport and manufacturing. 
However, the performance of the manufacturing sector in Nigeria shows that there are some vital problems that have and are still inhibiting the growth of the sector. It has also been argued that some basic limitations are impeding the growth and development of the sector despite past studies and solutions proffered.

Complete analysis of the Nigerian manufacturing sector is complex due to inadequate data about the productivity levels of the Nigerian economy. It has however been reported that the overall productivity level of the manufacturing sector from 1980-1989 has seen very increase and most of the companies even faced a decline in productivity. The report expressed low expectations of improvement in the situation. Studies conducted in the 1990s and 2000s confirmed this expectation of negative trend in productivity level of the sector ( $\mathrm{Ku}$ et al, 2010).

Meagher (2006) identified the problem of the Nigerian manufacturing sector from the perspective of inadequate academic research and development from the Nigerian universities and other institutions. He recommended that the research institutions in the country be adequately funded by the Nigerian government, public, private and even multinational organisations in order that the decaying manufacturing sector be revived through the researches that will be engaged in. It is against this backdrop that this research becomes a matter of necessity.

The performance of a manufacturing firm is often identified with the growth rate of potential output. However, in a non-manufacturing firm, potential output is not observed in reality but can be approximated. Measuring performance has been part and parcel of a successful manufacturing firm. It has to be strategic in that the survival of any organization depends on its performance. In other words, management uses performance measurement to evaluate the overall health of the organization.

The output of a firm is dependent mainly on factors of production, classified as labour and capital. The firm has to confront the problem of determining how much labour and capital to employ to produce the most efficient output. Every production manager wants to increase production level to the maximum point at the available factors of production. The right combination of these two factors to maximize output (productivity) of a production firm forms the basis of this study. The indigenous bottle manufacturing company under study has been in operation for over 25 years. The company is situated in Delta State of Nigeria. It comprises various departments, ranging from cold end department, printing department, mould department, quality control department, and process maintenance department. They operate a flow or mass production system. This means continuous production.

There is no doubt, that there is a link between potential output and its input variables. But the problem of establishing the right relationship between the input variable and the output variable (firm performance) still exist. When studying the growth of a nation's economy, the economists have established the link between input and output of the nation. But most of the individual firms in the economy have not been able to establish similar relationship that exists between the input and output of their production line. This study therefore establishes such a relationship using the Cobb-Douglass.

Some studies have been conducted using this model in different areas of research. The qualitative and quantitative explanation, the merits of the Cobb-Douglas production function and its use for analyzing production process because of the advantage it possesses which outweighs its advantages were identified by Bhanumurthy (2002). Effiong and Umoh (2010) used the Cobb-Douglas model based on stochastic profit frontier to estimate and the relevant indices determining efficiency levels for egglaying industry in Akwa Ibom state in Nigeria while (Banaeian and Zangeneh, 2011) used the model to obtain the relationship between agricultural inputs and walnut yield in view of energy input in Iran. Adinya et al (2011) examined the constraints militating against the profitability potentials of snail production by small-scale farmers in Cross River State, Nigeria utililsing the model. (Bhagwat and Debruine, 2011) utilized the production function approach to study the concomitant effect of Research and Development ( $\mathrm{R}$ and $\mathrm{D}$ ) and advertising expenditures on the revenue of pharmaceutical firms. Essi (2011) used the model to establish how the role played by production function in economics can be enhanced when they are correctly specified. Khater (2012) established a new index for human development based on the Cobb-Douglas function, for the purpose of measuring and assessing development among different overrates in Egypt. He also compared it with available indices and 
discovered that it outperformed them. However, literature that reported on using the model to analyse the productivity of the manufacturing sector in Nigeria is scarce hence the need for this study.

The aim of this study is to evaluate the productivity (firm's performance) of an indigenous bottle manufacturing firm located in Nigeria using Cobb-Douglass production function which will serve as a basis for future improved models to be developed for the company and similar outfits. The data used covered a period of 20 years (1991-2010). In addition to developing the production function for the company under study, the function is also optimized in order to get the least cost combination of input resources for a desired level of output. This study is intended to give a better understanding of performance measurement, serve as a guide to manufacturing as well as service companies and as a reference material for future research in this area for the manufacturing sector since lack of adequate information and data have been reported.

\subsection{Theoretical Framework}

The Cobb-Douglas production function expresses the relationship between productivity and factors of production. The model presents a simplified view of the economy in which production output is determined by the amount of labour involved and the amount of capital invested. In this regard, a lot of studies have been undertaken. The function is of the form:

$$
Q(L, K)=b L^{\alpha} K^{\beta}
$$

\subsubsection{Assumptions made in the Model}

If the production function denote by $Q=q(L, K)$, then the partial derivative. $\frac{\partial Q}{\partial L}$ is the rate at which production changes with respect to the amount of labour. Economists called it marginal productivity of labour. Likewise the partial derivative $\frac{\partial Q}{\partial K}$ is the rate at which production changes with respect to capital and is called the marginal productivity of capital (Bao Hong, 2008). In this term the assumption made by Cobb-Douglass can be state as follows:

i. If either labour or capital vanishes, them so will production.

ii. The marginal productivity of labour is proportional to the amount of production per unit of labour.

iii. The marginal productivity of capital is proportional to the amount of production per unit of capital.

Because the production per unit of labour is $\frac{P}{L}$, assumption 2 says that

$$
\frac{\partial Q}{\partial L}=\alpha \frac{Q}{L}
$$

Finally, $Q(L, k)=C_{1}\left(K_{0}\right) L^{\alpha}$

Where $\mathrm{C}_{1}\left(\mathrm{k}_{0}\right)$ is the constant of integration and we can write it as a function of $\mathrm{k}_{0}$ since it could depend on the value of $\mathrm{k}_{0}$.

Similarly, assumption 3 says that

$$
\frac{\partial Q}{\partial k}=\beta \frac{Q}{k}
$$

Keeping $\mathrm{L}$ constant $\left(\mathrm{L}=L_{0}\right)$ this differential equation can be solve to get

$$
Q\left(L_{0}, K\right)=C_{2}\left(L_{0}\right) K^{\beta}
$$

Finally, combining equation (3) and equation (4), we have

$$
Q\left(L_{0}, K\right)=b L^{\alpha} K^{\beta}
$$

Where $\mathrm{b}$ is a constant that is independent of both $\mathrm{L}$ and $\mathrm{K}$. 
Assumption 1 shows that $\alpha>0$ and $\beta>0$. From Equation 1, if labour and capital are both increased by a factor $M$, then,

$$
Q(M L, M K)=b(M L)^{\alpha}(M K)^{\beta}=M^{\alpha+\beta_{b}}=M^{\alpha+\beta} Q(L, K)
$$

From the theory of return to scale, if $\alpha+\beta=1, Q(M L, M k)=M Q(L, K)$ which means that production is also increased by a factor of $M$.

From equation 1 ,

$\log Q=\log b+\alpha \log k+\beta \log L$

$Y=P+\alpha X_{1}+b X_{2}$

Where $\mathrm{Y}=\log \mathrm{Q}, \mathrm{P}=\log b, X_{1}=\log \mathrm{K}$, and $X_{2}=\log \mathrm{L}$

For a multivariate linear regression analysis we use the model below:

$$
\begin{gathered}
Y=P+\alpha X_{1}+\beta X_{2} \\
\sum Y=n P+\alpha \sum X_{1}+\beta \sum X_{2} \\
\sum X_{1} Y=P X_{1}+\alpha \sum X_{1}^{2}+\beta \sum X_{1} X_{2} \\
\sum X_{2} Y=P X_{2}+\alpha \sum X_{1} X_{2}+\beta \sum X_{2}^{2}
\end{gathered}
$$

\subsection{Business Cycle}

Business cycle refers to a phenomenon of cyclical booms and depression. In a business, there are wavelike fluctuations in aggregate output. Business cycle has four phases namely: Prosperity, Recession, Depression and Recovery. Prosperity is a period in which output is at the highest peak. While recession starts when there is descent from the peak, which is of short duration. Depression is the lowest peak; it is as a result of the general decline in economic activity. There is a considerable reduction in the production of goods. When depression has lasted for some time then it will begin to rise, this phase is known as recovery.

\subsection{Methodology}

This research work involves the assessment of the productivity of a glass bottle manufacturing firm using the Cobb-douglass' Model with labour and capital as input variables to develop a muti-regression prediction model. This will be achieved by using secondary production input and output data obtained from the firm, covering a period of 20 years (1991 to 2010). The production function developed will be used to establish a production frontier against which actual production will be evaluated. Using Lagrange multipliers, the model can be optimized in order to get the least cost combination of input resources

\subsection{Data Collection}

The assumption made by Cobb- Douglass limited the factor of production to labour and capital as the input and the output of their production line. The labour index in this research work was obtained by summing the number of hours worked by those employees in the production floor. In this firm the employees work seven hours a day for shift workers and for straight day employees work eight hour a day. To obtain the capital index, we need the cost of production which includes the salary of workers in the production floor, money used to purchase raw material, and the book value of the machines that were used in the production process. Since most of the machines were not purchased during the period under study, and that they have passed through depreciation stages, we had to compute depreciation account to get the book value of the machines. In the production line of the firm, the different equipment used in the production process are listed thus:

1. Ande printing machine 2. Palletizing machine 3. Furnace 4. Iscebeg machine 5. Maipo stitching machine 6. Ringler rapping machine 7. Ximing power plants (1 and 2) 8. Fork lift 9. Howitt layer 10.Vensingh washing machine 11. Moser mixer machine 12. Panama driller 
These machines are fixed assets which are purchased for the production process. To know the cost of production, then we must know the monetary worth of these machines. Table 1 shows some basic history of these equipment. Table 1 displays information about cost, Useful life as well as salvage value and the date of purchase of equipment used in the production process as obtained from accounts department of the company.

Table 1: Information about equipment used in the production process

\begin{tabular}{|c|c|c|c|c|}
\hline Equipment & Date of Purchase & Asset Cost (\#) & Useful Life (yrs) & Salvage Value (\%) \\
\hline 1 & 05/01/1991 & $15,00,000$ & 25 & 10 \\
\hline 2 & 01/06/1999 & $5,000,000$ & 15 & 5 \\
\hline 3 & $27 / 12 / 1980$ & $50,000,000$ & 30 & 10 \\
\hline 4 & $30 / 12 / 1989$ & $1,000,000$ & 25 & 5 \\
\hline 5 & 31/05/1997 & 200,000 & 15 & 10 \\
\hline 6 & $10 / 01 / 2000$ & $4,000,000$ & 10 & 5 \\
\hline 7 (Power Plant1) & 21/01/1984 & $8,000,000$ & 15 & 109 \\
\hline (PowerPlant 2) & 01/06/2000 & $12,000,000$ & 15 & 10 \\
\hline 8 & 01/07/2000 & $2,000,000$ & 15 & 10 \\
\hline 9 & 30/11/1992 & $1,500,000$ & 15 & 10 \\
\hline 10 & 15/01/1998 & 150,000 & 15 & 5 \\
\hline 11 & $15 / 06 / 1998$ & $5,000,000$ & 15 & 10 \\
\hline 12 & 25/01/1990 & $9,000,000$ & 20 & 5 \\
\hline
\end{tabular}

\subsection{Data Analysis, Results and Discussion}

The figures in Table 1 were used to obtain the depreciation account for the period they served, starting with the year of purchase. The data was organized using the information available from the company. Table 2 shows the output and input figures for the period under study. The Double Declining Balance technique was used for depreciation since it is the company's policy.

\subsection{Depreciation Account}

The annual depreciation is calculated as follows:

Annual depreciation $=$ Depreciation rate $\times$ book value at the beginning of the year

The depreciation rate (Collier and Glagola, 1998) $=\frac{2}{\text { Useful life }}$

Purchase of depreciable asset is equal to book value at time zero and the cause of depreciation is mostly due to wear, which accumulates as a function of hours of use, severity of use and the level of preventive maintenance.

Table 2: Output and input figures

\begin{tabular}{|c|c|c|c|}
\hline Year & $(Q) \times 10^{10}$ & (L) $\quad \times 10^{7}$ & $(K) \times 10^{8}$ \\
\hline 1991 & 2.12675 & 6.99876 & 2.46739 \\
\hline 1992 & 2.00564 & 5.67250 & 2.32985 \\
\hline 1993 & 2.044598 & 5.93498 & 2.29515 \\
\hline 1994 & 1.14398 & 4.96819 & 1.96248 \\
\hline 1995 & 2.09484 & 6.19454 & 1.99606 \\
\hline 1996 & 2.11199 & 6.81410 & 1.98143 \\
\hline 1997 & 2.10671 & 6.20325 & 2.61265 \\
\hline 1998 & 2.07154 & 6.40017 & 4.92822 \\
\hline 1999 & 2.06981 & 6.57259 & 2.02132 \\
\hline 2000 & 2.03180 & 5.56691 & 2.20062 \\
\hline 2001 & 2.01905 & 5.66494 & 2.28092 \\
\hline 2002 & 2.08104 & 6.75498 & 2.23576 \\
\hline 2003 & 2.07213 & 6.61760 & 2.18136 \\
\hline 2004 & 2.00937 & 5.73978 & 2.23649 \\
\hline 2005 & 1.14080 & 5.18900 & 1.98752 \\
\hline 2006 & 2.13837 & 6.34180 & 1.78799 \\
\hline 2007 & 1.15287 & 5.01213 & 1.66944 \\
\hline 2008 & 1.13901 & 7.09935 & 2.05942 \\
\hline 2009 & 2.15957 & 7.17010 & 1.87993 \\
\hline 2010 & 2.07964 & 6.57259 & 2.02267 \\
\hline
\end{tabular}


The data obtained were analysed using the ordinary least square multiple regression technique to establish the relationship between the output variable and the input variables given as:

$\sum y=205.30740, \sum X_{1}=155.75568, \sum X_{2}=166.83115, \sum X_{1}{ }^{2}=1213.03697, \sum X_{2}{ }^{2}=1391.83255$, $\sum Y X_{1}=1598.88138, \sum Y X_{2}=1712.5758$ and $\sum X_{1} X_{2}=1299.25911$.

Solving the regression equations (equations (9) to (12)) with the data gives:

$\alpha=-0.35639, \beta=0.55603$ and $\mathrm{P}=8.40275$

From equation $9, b=10^{p}$ hence, $\mathrm{b}=2.51189 \times 10^{8}$.

Substituting these estimators into equation 1 , we have:

$\mathrm{Q}=2.51189 \times 10^{8} L^{-0.35639} K^{0.55603}$

Table 3 shows the percentage deviation between the actual and theoretical production.

Table 3: Percentage Deviation between Actual Production and Theoretical Production.

\begin{tabular}{|c|c|c|c|c|}
\hline .Years & $\begin{array}{l}\text { Actual Production } \\
\mathbf{Q} \times 10^{10}\end{array}$ & $\begin{array}{l}\text { Theoretical Production } \\
\qquad q \times 10^{10}\end{array}$ & $\begin{array}{l}\text { Percentage Deviation } \\
\frac{Q-q}{Q} \times 100\end{array}$ & $\begin{array}{l}\text { Business } \\
\text { Cycle }\end{array}$ \\
\hline 1991 & 2.12675 & 1.90830 & 10.27154 & Prosperity \\
\hline 1992 & 2.00564 & 1.99239 & 0.66064 & Recession \\
\hline 1993 & 2.04597 & 1.95444 & 51.16555 & Prosperity \\
\hline 1994 & 1.14396 & 1.92060 & -67.89048 & Depression \\
\hline 1995 & 2.09484 & 1.71294 & 18.23050 & Recovery \\
\hline 1996 & 2.11199 & 1.80216 & 14.66990 & Prosperity \\
\hline 1997 & 2.10671 & 1.82097 & 13.56333 & Prosperity \\
\hline 1998 & 2.07154 & 1.80326 & 12.95075 & Prosperity \\
\hline 1999 & 2.06981 & 1.76222 & 14.86078 & Prosperity \\
\hline 2000 & 2.03180 & 1.99348 & 1.88601 & Prosperity \\
\hline 2001 & 2.01905 & 1.94831 & 3.50362 & Prosperity \\
\hline 2002 & 2.08104 & 1.78703 & 14.12803 & Prosperity \\
\hline 2003 & 2.07213 & 1.85672 & 10.39558 & Prosperity \\
\hline 2004 & 2.00937 & 1.97094 & 1.91254 & Prosperity \\
\hline 2005 & 1.11408 & 1.79563 & -61.17604 & Depression \\
\hline 2006 & 2.13837 & 1.67058 & 21.87600 & Recession \\
\hline 2007 & 1.15287 & 1.77421 & -53.89506 & Depression \\
\hline 2008 & 1.13901 & 1.83886 & -61.44371 & Depression \\
\hline 2009 & 2.15957 & 1.67842 & 22.27989 & Recovery \\
\hline 2010 & 2.07964 & 1.70623 & 17.95551 & Recession \\
\hline
\end{tabular}

\subsection{Optimization of Function}

The objective function is (Ekanem and Iyoha, 1999):

$$
\mathrm{Q}=P_{l} \mathrm{~L}+P_{k} \mathrm{~K}
$$

If the firm desires to produce an output of $250 \times 10^{8}$ unit, how many unit of input of labour and capital should the firm employed to achieve their target if the unit price of labour per hour is $\$ 250$ while that of capital per unit hour is $\$ 300$.

The Lagrange function is

$$
\begin{aligned}
& \mathrm{Q}=2.51189 \times 10^{8} L^{-0.35639} K^{0.55603}+\lambda\left(250 \times 10^{8}-250 \mathrm{~L}-300 \mathrm{~K}\right) \\
& \frac{\delta Q}{\delta L}=-8.95 \times 10^{9} L^{-1.35639} K^{-0.55603}-250 \lambda \\
& \frac{\delta Q}{\delta K}=1.396 \times 10^{8} L^{-0.35639} K^{0.44397}-300 \lambda \\
& \frac{\delta Q}{\delta \lambda}=250 \times 10^{8}-250 \mathrm{~L}-300 \mathrm{~K}
\end{aligned}
$$

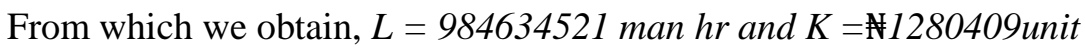


Under elasticity of substitution isoquant curve are generally convex to the origin its slope is always negative thus the sign of elasticity is negative. Economist conventionally eliminates this negative sign by multiplying through with -1 . More importantly, it is the absolute size that is of significance to the economist.

\subsection{Discussion of Results}

From eq. 14, $\alpha+\beta<1$ implying decreasing return to scale i.e. successive application of equal additional unit of variable input unto the existing fixed input will yield progressively less and less additional output.

The production frontier characterizes the maximum output with various input combination. To establish the theoretical output for a particular manufacturing year, the inputs for that year will be substituted into the production function. This is the production frontier against the actual production is evaluated. For a particular year, if the firm operates above the production frontier (if the actual production is more than the theoretical production) for a manufacturing year, the firm is technically efficient, otherwise, the firm is technically inefficient.

Table 3 indicated that for 80 percent of the years under study, the firm operated above the production frontier, meaning that they were technically efficient in their use of input resources. With the exception of 1994, 2005, 2007 and 2008 where the firm operated below the production frontier.

From the foregoing, it is noticed that there is difference between what was actually produced and the computed production. The deviation between the actual production and theoretical production follows the Business cycle. According to Baxter and King (1999), positive deviations indicate prosperity, while negative deviations indicate recession.

Production was at its peak in 2009 with an output of $215.9 \times 10^{8}$ units followed by 2006 with an output of $213.8 \times 10^{8}$ and 1991 with an output of $212.7 \times 10^{8} \mathrm{~A}$ careful look at the chart showed that there was a sudden drop in production for the years 1994, 2005, 2007, and 2008.with an output of $114.4, \times 10^{8}$ $111.4 \times 10^{8} 115.3 \times 10^{8}$ and $113.9 \times 10^{8}$ unit.Productivity fluctuates between $200 \times 10^{8}$ unit and 220 $\times 10^{8}$ unit within the years 1995 and 2004 . Looking closely at the trend on the graph shows from times series analysis that production has the tendency to decrease as time goes on.

There were positive and negative deviations. Its highest positive deviation occurred in the year 2009 with peak deviation of 22.28 percent and the lowest deviation occurred for the year 1994 with a deviation of -67.89 percent deviation and the trend line indicates a decrease in the near future.

The productivity of each factor can be examined when one of the factor input is held constant. As the unit of labour increase and capital held constant, production will increase. But if labour is held constant while capital is increase, then production will decrease. It implies that more of labour and less capital will result in output growth.

The unit of labour and capital that the firm needs to employ to achieve a desired output of $250 \times 10^{8}$ units is 984634521 man-hr and $\$ 1280409$. Anything less than this value will result in a different output.

\subsection{Conclusion}

The production function of the indigenous firm under study has been developed and optimised. With the model we were able to evaluate and come to the conclusion that for 80 percent of the years under study the firm's output performance was efficient with the exception of 1994, 2005, 2007, and 2008. With the desired output of $250 \times 10^{8}$ and with unit price of labour to be $\$ 250$ per hour and that of capital is $\$ 300$, the model has been used to estimate the amount of input (labour and capital) to be applied to the production line to achieve the desire output. The amount of labour that should be applied is 984634521 hours and that for capital is 1280409 . 


\section{References}

Adinya, I.B., Edet, D., Nyienakuna, M.G. and Ikpi, G.U. (2011) Estimation of Efficiency Constraints using Cobb-Douglass Production Function in Snail (Archacha Marginata). Production by Small Farmers in Cross Rivers State, Nigeria, J. Anim and Pl Sci, 21(2) pp. 274-282.

Banaeian, N and Zangeneh, M. (2011) Estimating Production Function of Walnut Production in Iran using Cobb-Douglas Method, J. Agricultural Tropica et Subtropical, 44 (4) pp.177-189.

Bao Hong, T. (2008) Cobb-Douglas Production Function, 1-7 Unpublished. http://www.fe.unl.pt/ jamador/macro/cobb-douglas.pdf. Retrieved on 22 ${ }^{\text {nd }}$ April, 2014.

Collier, C.A. and Glagola, C.R. (1998) Engineering Economic and Cost Analysis. third ed., AddisonWesley, California.

Baxter, M. and King, R.G. (1999) Measuring Business Cycles: Approximate Band-Pass Filters for Economic Time Series, J. Rev. Eco. Stat., 81(4) 575-593.

Bhagwat, Y. and DeBruine, M. (2011) R and D and advertising Efficiencies in the Pharmaceutical Industry, Int. J. Appl. Eco., 8(1) 55-65.

Bhanumurthy, K.V. (2002) Arguing a Case for the Cobb-Douglas Production Function, Rev. of Comm. Stud, Del, Ind, (2002) 75-89.

Effiong, E.O. and Umoh, G.S. (2010) Cobb Douglas Production Function with Composite Error Term in Egg Laying Enterprise in Akwa Ibom State, Nigeria. J. Trop. Agric., Fd, Env. and Ext., 9(1) pp. 1-7.

Ekanem, O.T. and Iyoha, M.A. (1999) Microeconomic Theory, First ed., Mareh Publishers, Benin City, Nigeria.

Essi, I.D. (2011) On Policy Relevance of Correct Appreciation for Production Functions, Am. J. Soc. Mgmt. Sci. 2(3) pp. 291-294.

Khater, E. (2012) A Cobb-Douglas Function Based Index for Human Development in Egypt, Int. J. Contemp. Math. Sciences, 7(12) pp. 591-598.

Ku, U., Mustapha, U. and Goh, S. (2010) A Literature Review of Past and Present Performance of Nigerian Manufacturing Sector, J. Eng. Manuf. 224(12) 1894-1904.

Meagher, K. (2006) Social Capital, Social Liabilities and Political Capital: Social Networks and Informal Manufacturing in Nigeria, J. Afri. Affairs. Pp. 553-582.

Report of the Vision 2020 National Technical Working Group on Manufacturing Thematic Area, July 2009. www.npc.gov.ng/vault/files/manufacturing ntwg report.pdf. Retrieved $21^{\text {st }}$ April, 2014. 